\title{
Dynamic expression of miR-206-3p during mouse skin development is independent of keratinocyte differentiation
}

\author{
YUAN MU ${ }^{1,2}$, HONG ZHOU $^{2}$, WEI-JIANG WU ${ }^{3}$, LI-CHAO HU ${ }^{2}$ and HONG-BING CHEN ${ }^{1}$ \\ ${ }^{1}$ Department of Clinical Laboratory, Nanjing Children's Hospital, Nanjing Medical University, Nanjing, Jiangsu 210008; \\ Departments of ${ }^{2}$ Clinical Laboratory and Hematology, and ${ }^{3}$ Histology and Embryology, \\ School of Medicine, Jiangsu University, Zhenjiang, Jiangsu 212013, P.R. China
}

Received December 24, 2014; Accepted September 16, 2015

DOI: $10.3892 / \mathrm{mmr} .2015 .4456$

\begin{abstract}
MicroRNA-206 (miR-206), the homolog of which in mice is termed miR-206-3p, is a muscle-specific miRNA known to be important in the development of skeletal muscle, and is involved in smooth muscle innervation of the airway through the post-transcriptional suppression of brain-derived neurotrophic factor $(B d n f)$. miR-206-3p is also expressed at significant levels in adult and embryonic skin; however, its functional roles in adult skin and during skin development remain to be fully elucidated. In the present study, the spatiotemporal expression of miR-206-3p and its target-gene, Bdnf, during mouse skin development were investigated. The expression level of miR-206-3p increased from 13.5 days postcoitus (dpc), peaked at $17.5 \mathrm{dpc}$ and declined following birth. The observed temporal profile of the expression of miR-206-3p was accompanied by an inverse change in the protein expression levels of BDNF. However, the mRNA expression levels of $B d n f$ did not parallel those of BDNF protein. The localization of the expression of miR-206-3p was similar, or located near that of ubiquitin carboxyl-terminal hydrolase L1 during skin development. An in vitro keratinocyte model demonstrated no significant differences between primary and differentiated keratinocytes in the expression levels of either miR-206-3p $(\mathrm{P}=0.227$ ) or $B d n f$ (mRNA, $\mathrm{P}=0.118$; mature BDNF, $\mathrm{P}=0.106$; pro-BDNF, $\mathrm{P}=0.905)$. These findings indicate a potential role for miR-206-3p in cutaneous innervation, which largely relies on BDNF neurotrophic support and is independent of keratinocyte differentiation. The results of the present study suggested that this novel mechanism may be targeted for developing potential therapeutic approaches.
\end{abstract}

Correspondence to: Professor Hong Zhou, Department of Clinical Laboratory and Hematology, School of Medicine, Jiangsu University, 301 Xuefu Road, Zhenjiang, Jiangsu 212013, P.R. China

E-mail: hongzhou@ujs.edu.cn

Key words: microRNA-206, brain-derived neurotrophic factor, skin development, cutaneous innervations, keratinocyte

\section{Introduction}

miRNA-206 is known as a muscle-specific miRNA, one of the so-called myomiRs, and has been consistently found using northern blotting, microarray, RNase protection and quantitative polymerase chain reaction (qPCR) analyses to be specifically expressed in skeletal muscle, but rarely detectable in other adult tissues (1). Its primary transcript, contained in a synapse-associated 7H4 non-coding RNA, was first identified in the motor endplate of the rat skeletal neuromuscular junction, long before the 'microRNA era' (2). Accumulated evidence has shown that miR-206 is important in the growth and development of skeletal muscle through targeting a number of genes, including gap junction protein $\alpha-1$ (3), polymerase (DNA directed) $\alpha-1$ (4), follistatin-like 1 (5), utrophin (5), paired box 7 (6) and histone deacetylase 4 (7). In a model of amyotrophic lateral sclerosis, a novel pathway for neuromuscular synapse repair regulated by miR-206 has been identified (8). This indicates that miR-206 may be a key modulator in establishing muscular function through coordinating innervation. A previous study reported that sonic hedgehog signaling inhibited the expression of miR-206, which increased the protein levels of brain-derived neurotrophic factor (BDNF), an essential signal for airway smooth muscle innervation (9). This further supports the neuronal function of miR-206 in a muscular context.

The expression of miR-206 has also been detected at significant levels in adult mouse skin using RNase protection assays (3); however, no further investigation of miR-206 in skin has been reported. Another two reports demonstrated that miR-206 is downregulated in human melanoma biopsies (10) and in skin from human papillomavirus 8-transgenic mice (11). Our previous study found that the mouse homolog of hsa-miR-206, miR-206-3p, was often expressed in embryonic skin at a level, which was one quarter of the level in skeletal muscle (12). Several other skin-specific or skin-associated miRNAs have been identified $(13,14)$ and, in comparison, miR-206 is expressed at relatively low levels in adult skin. However, its expression profile in embryonic skin remains to be fully elucidated. In a previous screen of differentiating keratinocyte (KC) miRNAs, miR-206 was not identified (14), although it had muscular and neuronal functions in muscle. Therefore, the present study hypothesized that miR-206 is 
involved in skin development, possibly through an association with neurofunction. To confirm this hypothesis, the present study investigated the spatial and temporal expression of miR-206-3p and its target gene, $B d n f$, during mouse skin development, and determined whether the dynamic expression of miR-206-3p is involved in the KC differentiation program.

\section{Materials and methods}

Mice and tissue samples. Wild-type BALB/c mice were bred and maintained in accordance with the Principles of Laboratory Animal Care at the Laboratory Animal Center of Jiangsu University (Zhenjiang, China; License no. SYXK [SU] 2008-0024) in a temperature and humidity-controlled room maintained in a $12 \mathrm{~h}$ light/dark cycle with food and water ad libitum. All animal experiments in the present study were approved by the ethics committee of Jiangsu University. Mature (6-12 week-old) female mice were housed separately until natural mating with a 2:1 female to male ratio, and were assessed for vaginal plug formation on the morning following mating. Females with vaginal plugs were designated as 0.5 day postcoitum (dpc), and neonatal mice on the day of delivery were designated as 1 day postpartum (dpp). Full-thickness skin and subcutaneous muscle were dissected for cryosections and TRIzol ${ }^{\circledR}$ homogenization (Invitrogen; Thermo Fisher Scientific, Inc., Waltham, MA, USA), respectively. Pregnant females at various stages of gestation were intraperitoneally anesthetized with $1 \%$ pentobarbital sodium (35-50 mg/kg; Sigma-Aldrich, St. Louis, MO, USA) and embryos were collected by cesarean section. A skin tissue sample of $3 \times 3 \mathrm{~mm}$ and a $3 \mathrm{~mm}^{3}$ subcutaneous skeletal muscle tissue sample were dissected from the back of the embryos of at least three different mothers at each time-point. Following tissue harvest, the anesthetized mice were sacrificed by cervical dislocation. The harvested tissues were snap-frozen in liquid nitrogen prior to being stored at $-80^{\circ} \mathrm{C}$.

Cryosections. The frozen tissues were embedded in Tissue-Tek ${ }^{\circledR}$ OCT $^{\text {Tм }}$ (Sakura Finetek, Tokyo, Japan) and cut at a thickness of 8-10 $\mu \mathrm{m}$ on a CM1900 freezing microtome (Leica Microsystems $\mathrm{GmbH}$, Wetzlar, Germany). The cryosections were mounted on poly-L-lysine coated slides (Wuhan Boster Biological Technology, Ltd., Wuhan, China), following which the slides were air-dried for $10 \mathrm{~min}$, fixed for $10 \mathrm{~min}$ with $4 \%$ paraformaldehyde (Sangon Biotech Co., Ltd., Shanghai, China), rinsed with Dulbecco's phosphate-buffered saline (PBS) and stored at $-20^{\circ} \mathrm{C}$ following thorough drying.

In situ hybridization (ISH). The frozen sections were air-dried for $\sim 15$ min, following which hybridization was performed using an Enhanced Sensitive ISH Detection kit (cat. no. MK1032; Wuhan Boster Biological Technology, Ltd.), according to the manufacturer's protocol. Briefly, the sections were treated with pepsin supplied in the Enhanced Sensitive ISH Detection kit at $37^{\circ} \mathrm{C}$ for $5 \mathrm{~min}$, washed with $0.5 \mathrm{M}$ Tris-buffered salin (TBS; Sangon Biotech Co., Ltd.) and then $0.1 \%$ diethylpyrocarbonate-treated water (Sangon Biotech Co., Ltd.), pre-hybridized at $40^{\circ} \mathrm{C}$ for $1 \mathrm{~h}$, and then hybridized with $100 \mathrm{nM}$ 5'-digoxigenin (DIG)-labeled LNA $^{\mathrm{TM}}$ probe (Exiqon A/S, Vedbaek, Denmark) against miR-206 at $50^{\circ} \mathrm{C}$ for $8 \mathrm{~h}$. Following hybridization, the slides were washed with 2x saline sodium citrate (SSC; Sangon Biotech Co., Ltd.), 0.5x SSC, 0.2x SSC, sequentially. Subsequently, the slides were blocked using the blocking solution supplied in the Enhanced Sensitive ISH Detection kit for $30 \mathrm{~min}$ at $37^{\circ} \mathrm{C}$, and incubated with biotinylated anti-DIG antibody (supplied in the Enhanced Sensitive ISH Detection kit) for $2 \mathrm{~h}$ at $37^{\circ} \mathrm{C}$. Following washing with $0.5 \mathrm{M}$ TBS, alkaline phosphatase (AP)-conjugated streptavidin (supplied in the Enhanced Sensitive ISH Detection kit) was applied to the section for $1 \mathrm{~h}$ at room temperature. Immediately following washing of the slides, AP substrate, containing $0.2 \mathrm{mM}$ levamisol, was prepared and then applied to the sections in the dark at $30^{\circ} \mathrm{C}$ for $2 \mathrm{~h}$. When the desired intensity of chromogenic reaction was reached (strongly stained target and unstained background), the slides were washed with water, followed by mounting in aqueous medium and imaging on a DM LB2 microscope (Leica Microystems GmbH).

Immunohistochemistry (IHC). The frozen sections were air-dried and incubated for heat-induced antigen retrieval in $0.01 \mathrm{M}$ citrate buffer ( $\mathrm{pH}$ 6.0; Sangon Biotech Co., Ltd.) at $100^{\circ} \mathrm{C}$ for $10 \mathrm{~min}$. Following cooling to room temperature, $0.6 \%$ $\mathrm{H}_{2} \mathrm{O}_{2} / 80 \%$ methanol was applied to the sections for $10 \mathrm{~min}$ at room temperature to eliminate endogenous peroxidation. Following washing with D-PBS, the sections were blocked with $10 \%$ bovine serum albumin (Sangon Biotech Co., Ltd.) and $0.2 \%$ Triton X-100 (Sangon Biotech Co., Ltd.) in D-PBS for $30 \mathrm{~min}$ at room temperature, prior to incubation with anti-mouse BDNF rabbit polyclonal antibody (cat. no. BA0565; Wuhan Boster Biological Technology, Ltd.) diluted 100-folds or anti-mouse ubiquitin carboxy-terminal hydrolase L1 (UCHL1) rabbit polyclonal antibody (cat. no. BS1293; Bioworld Technology, Inc. St. Louis Park, MN, USA) diluted 80-folds at $4^{\circ} \mathrm{C}$ overnight. Following washing with PBS with $0.1 \%$ Tween 20 (PBS-T; Sangon Biotech Co., Ltd.), the sections were added with horseradish peroxidase (HRP)-conjugated goat anti-rabbit IgG antibody (cat. no. BA1055; Wuhan Boster Biological Technology, Ltd.) diluted 500-fold for $2 \mathrm{~h}$ at room temperature. Following washing with PBST, $1 \% \mathrm{H}_{2} \mathrm{O}_{2}$ was diluted 100 -fold with $0.05 \%$ diaminobenzidine (Sangon Biotech Co., Ltd.) in TBS to prepare an active substrate solution, which was then applied to the sections for color development. The reaction was terminated by washing, following which the sections were counterstained with hematoxylin, dehydrated with alcohol, mounted with neutral balsam and imaged on a DM LB2 microscope (Leica Microsystems $\mathrm{GmbH}$ ).

Cell culture and in vitro differentiation. To determine cell differentiation, three independent back skin biopsies $(5 \mathrm{~mm} \times 2 \mathrm{~cm})$ from $1 \mathrm{dpp}$ mouse were used to isolate epidermal keratinocytes. Firstly, the skin biopsies were washed three times in D-PBS containing high-concentration antibiotics (200 U/ml penicillin and $200 \mathrm{U} / \mathrm{ml}$ streptomycin; Sangon Biotech Co., Ltd.) for $5 \mathrm{~min}$, and subcutaneous residues were curetted. Secondly, the epidermis of each skin biopsy was separated from the dermal compartment using $0.3 \%$ Dispase $^{\circledR}$ II (Roche Diagnostics GmbH, Mannheim, German) digestion overnight at $4^{\circ} \mathrm{C}$. Subsequently, the epidermal sheets were trypsinized with $0.25 \%$ trypsin-EDTA (Invitrogen; Thermo Fisher Scientific, Inc.) for $10 \mathrm{~min}$ at $37^{\circ} \mathrm{C}$, followed by the addition of $0.1 \%$ soybean trypsin inhibitor (Sigma-Aldrich) 
Table I. Primers used in the RT-qPCR assay.

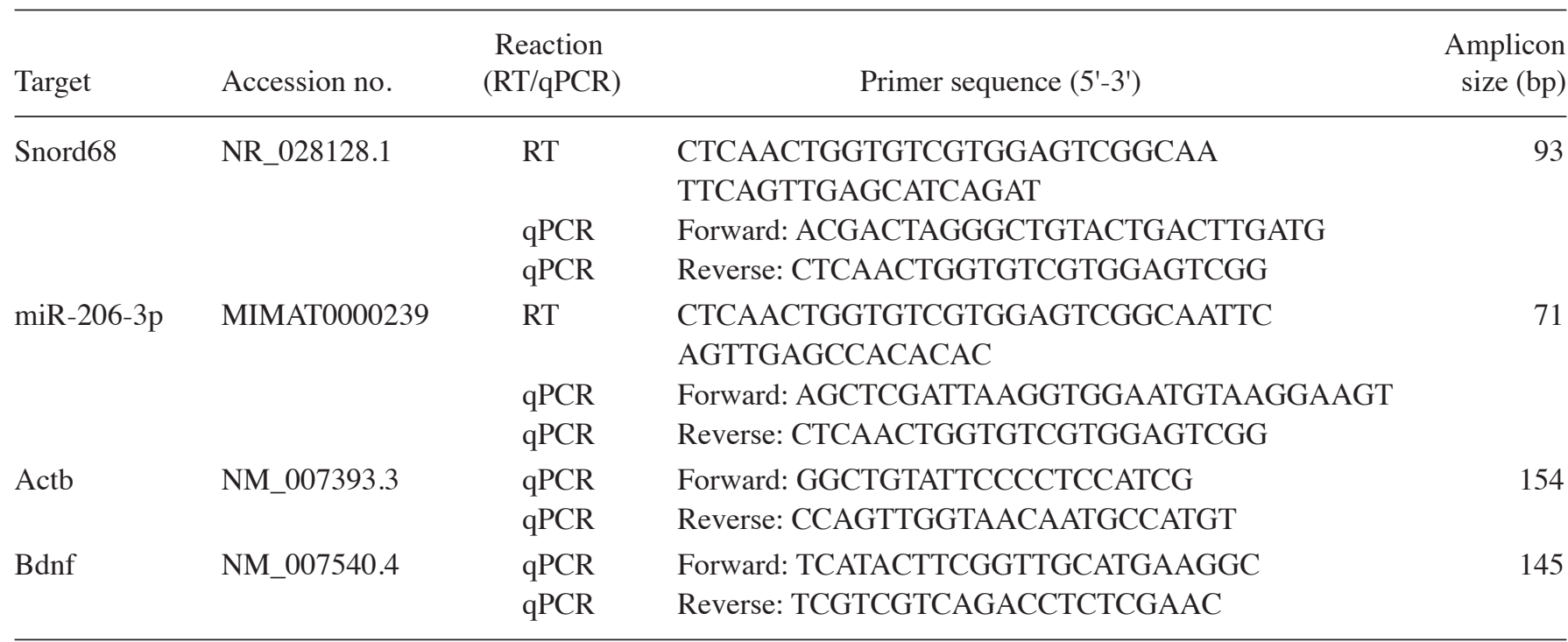

RT-qPCR, reverse transcription-quantitative polymerase chain reaction; miR, microRNA; Actb, $\beta$-actin; Bdnf, brain-derived neurotrophic factor.

at a 1:1 volume ratio to trypsin-EDTA, and were subsequently filtered to yield single cell suspensions. The keratinocytes were cultured in defined keratinocyte-serum-free medium (Invitrogen; Thermo Fisher Scientific, Inc.), and seeded at a density of $10^{5} / \mathrm{cm}^{2}$ on $2 \%$ gelatin coated dishes at $37^{\circ} \mathrm{C}$ and $5 \%$ $\mathrm{CO}_{2}$ to near confluency.

For in vitro differentiation, the primary keratinocytes cultured under standard conditions to $\sim 70 \%$ confluency were induced by increasing the calcium concentration of the growth medium to $1 \mathrm{mM}$ for 5 days.

$R N A$ extraction and reverse transcription $(R T)-q P C R$. Total RNA extraction was performed according to the manufacturer's protocol. Total RNA was extracted using TRIzol ${ }^{\circledR}$ (Invitrogen; Thermo Fisher Scientific, Inc.); prior to the addition of $0.2 \mathrm{ml}$ chloroform (Sangon Biotech Co., Ltd.) per $1 \mathrm{ml} \mathrm{TRIzol}{ }^{\circledR}$. The samples were then centrifuged at $12,000 \mathrm{x}$ g for $15 \mathrm{~min}$ at $4^{\circ} \mathrm{C}$, and the aqueous phase was then placed into another tube with an equal volume of $100 \%$ isopropanol (Sangon Biotech Co., Ltd.). Precipitation was conducted at $-20^{\circ} \mathrm{C}$ overnight as opposed to at room temperature for $10 \mathrm{~min}$ as previously described (15), and then centrifuged at $12,000 \mathrm{x}$ g for $10 \mathrm{~min}$ at $4^{\circ} \mathrm{C}$. The RNA pellet was washed twice with $1 \mathrm{ml}$ of $80 \%$ ethanol (Sangon Biotech Co., Ltd.) at 7,500 x g for $5 \mathrm{~min}$ at $4^{\circ} \mathrm{C}$, prior to being air dried for 5-10 min, and dissolved in RNase-free water (Sangon Biotech Co., Ltd.). RNA concentration was measured using a NanoDrop 1000 UV/Vis spectrophotometer (Thermo Fisher Scientific, Inc.). Prior to the RT reaction, the RNAs were treated with DNase (NEB, Ipswich, MA, USA), according to the manufacturer's protocol.

For amplification of $\beta$-actin (Actb) and Bdnf, cDNAs were generated using a ReverTra Ace- $\alpha-{ }^{\circledR}$ Reverse Transcription kit (Toboyo Co., Ltd., Osaka, Japan). According to the manufacturer's instructions, the reaction was performed using $500 \mathrm{ng}$ total RNA in a $10 \mu \mathrm{l}$ total volume, as follows: $30^{\circ} \mathrm{C}$ for $10 \mathrm{~min}, 42^{\circ} \mathrm{C}$ for $30 \mathrm{~min}$ and $99^{\circ} \mathrm{C}$ for $5 \mathrm{~min}$, and stored at $-20^{\circ} \mathrm{C}$. The miR-206-3p and Snord68 primers for RT and qPCR were designed according to a previous report (12). A pulsed gene-specific RT reaction (16) in a $10 \mu$ l total volume containing $500 \mathrm{ng}$ RNA and stem-loop primer (4 $\mathrm{nM}$ for miR-206-3p, $1 \mathrm{nM}$ for Snord68) was applied, as follows: $16^{\circ} \mathrm{C}$ for $30 \mathrm{~min}$, followed by 60 cycles at $20^{\circ} \mathrm{C}$ for $30 \mathrm{sec}, 42^{\circ} \mathrm{C}$ for $30 \mathrm{sec}$ and $50^{\circ} \mathrm{C}$ for $1 \mathrm{sec}$, with a final step at $99^{\circ} \mathrm{C}$ for $5 \mathrm{~min}$ and storage at $-20^{\circ} \mathrm{C}$.

A DyNAmo ${ }^{\mathrm{TM}}$ ColorFlash SYBR ${ }^{\circledR}$ Green qPCR kit (Thermo Fisher Scientific, Inc.) was used in a modified protocol regarding the volumes of reagents and cDNA in the $10 \mu \mathrm{l}$ total volume: $5 \mu \mathrm{l} 2 \mathrm{X}$ master mix, $1 \mu \mathrm{l}$ RT product, forward and reverse primer pairs (180 nM for Actb, Bdnf and miR-206-3p; $100 \mathrm{nM}$ for Snord68). A three-step qPCR was performed for Actb and Bdnf, as follows: $95^{\circ} \mathrm{C}$ for $7 \mathrm{~min}$; 40 cycles of denaturation at $95^{\circ} \mathrm{C}$ for $15 \mathrm{sec}$, annealing at $60^{\circ} \mathrm{C}$ for $20 \mathrm{sec}$ and extension at $72^{\circ} \mathrm{C}$ for $15 \mathrm{sec}$. A two-step qPCR was performed for Snord68 and miR-206-3p, as follows: $95^{\circ} \mathrm{C}$ for $7 \mathrm{~min}$; 40 cycles of denaturation at $95^{\circ} \mathrm{C}$ for $10 \mathrm{sec}$ and extension (Snord68 at $66^{\circ} \mathrm{C}$; miR-206-3p at $59^{\circ} \mathrm{C}$ ) for $30 \mathrm{sec}$. All primers (Table I) were synthesized by Sangon Biotech Co., Ltd.

All RT-qPCR reactions, including the RT minus controls and no-template controls, were run in triplicate on an $\mathrm{CFX}^{\mathrm{TM}}$ 96 Real-Time PCR Detection System (Bio-Rad Laboratories, Inc., Hercules, CA, USA). The quantification cycle (Cq), defined as the fractional cycle number at which the fluorescence passes the fixed threshold, was determined using CFX Manager ${ }^{\mathrm{TM}}$ Software version 1.6 (Bio-Rad Laboratories, Inc.). The expression levels of miR-206-3p and Bdnf were calculated using the $\Delta \mathrm{Cq}$ method (17) using Snord68 and Actb as a reference, respectively.

Western blotting. Following removal of the RNA aqueous phase from the TRIzol ${ }^{\circledR}$ homogenate, the remaining phenol-chloroform layer was used for protein isolation, according to 
A

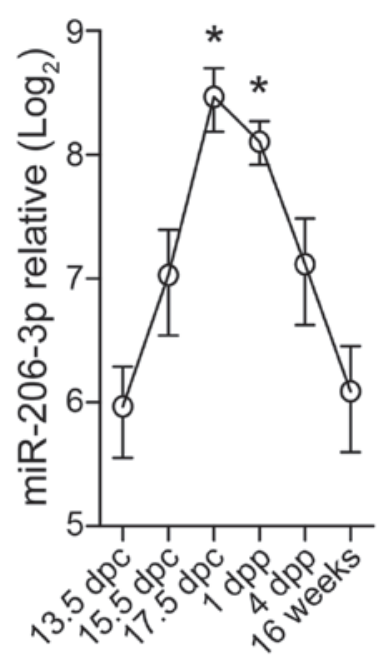

B

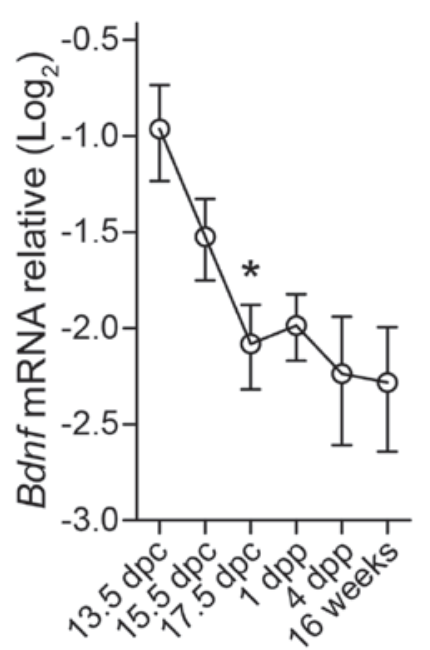

C

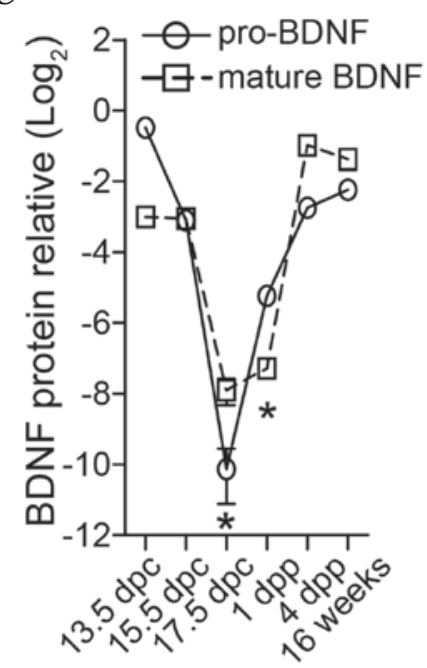

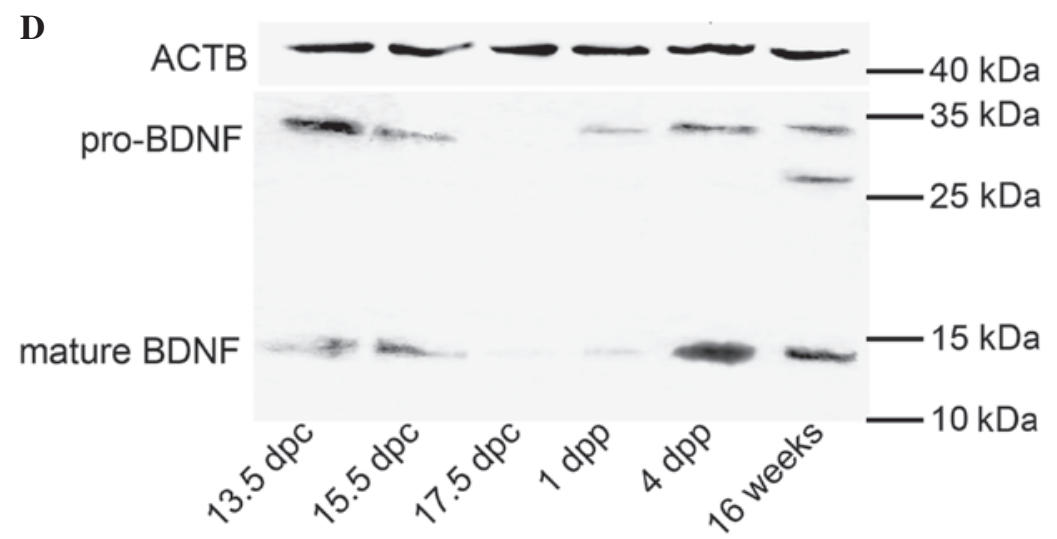

Figure 1. Full-thickness skin tissue from the backs of wide-type BALB/c mice at $13.5 \mathrm{dpc}, 15.5 \mathrm{dpc}, 17.5 \mathrm{dpc}, 1 \mathrm{dpp}, 4 \mathrm{dpp}$ and $16 \mathrm{weeks}$ postpartum were measured for the expression of (A) miR-206-3p, normalized to Snord68 and the (B) mRNA expression of Bdnf, normalized to Actb using reverse transcription-quantitative polymerase chain reaction analyses. (C and D) Protein expression of BDNF, normalized to ACTB was determined using western blotting. All relative expression data are plotted in $\log _{2}$ scale using the mean standard deviation from three independent samples. ${ }^{*} \mathrm{P}<0.05$, vs. 13.5 dpc. dpc, days postcoitum; dpp, days postpartum; miR, microRNA; BDNF, brain-derived neurotrophic factor; ACTB; $\beta$-actin.

manufacturer's protocol. A total of $1.5 \mathrm{ml}$ isopropanol was added per of $1 \mathrm{ml} \mathrm{TRIzol}{ }^{\circledR}$ for $10 \mathrm{~min}$ at room temperature, prior to being centrifuged at $12,000 \mathrm{x}$ g for $10 \mathrm{~min}$ at $4^{\circ} \mathrm{C}$. The protein pellet was washed three times with $2 \mathrm{ml}$ of $0.3 \mathrm{M}$ guanidine hydrochloride (Sangon Biotech Co., Ltd.) in $95 \%$ ethanol at 7,500 x g for $5 \mathrm{~min}$ at $4^{\circ} \mathrm{C}$, and once with $2 \mathrm{ml}$ of $100 \%$ ethanol. The protein pellet was subsequently air dried for 5-10 min, and dissolved in 0.5\% SDS/3 M urea (Sangon Biotech Co., Ltd.). The proteins were quantified using a bicinchoninic acid assay kit (CWBio, Beijing, China). Subsequently, the samples were denatured at $95^{\circ} \mathrm{C}$ for $5 \mathrm{~min}$, and $30 \mu \mathrm{g}$ proteins per lane were separated using 12\% SDS-PAGE and transferred onto Immobilon ${ }^{\circledR}$-P membranes (EMD Millipore, Billerica, MA, USA). The membranes were blocked in $5 \%$ defatted milk for $1 \mathrm{~h}$ at room temperature, and were then probed with anti-mouse ACTB rabbit polyclonal antibody (cat. no. 20536-1-AP; ProteinTech, USA) diluted 2,000-fold, anti-BDNF rabbit polyclonal antibody (cat. no. PB0013; Wuhan Boster Biological Technology, Ltd.) diluted 250-fold and rabbit anti-mouse involucrin (IVL) polyclonal antibody (cat. no. 55328-1-AP; ProteinTech, USA) diluted 300-fold, respectively, at $4^{\circ} \mathrm{C}$ overnight. Following washing with PBST,

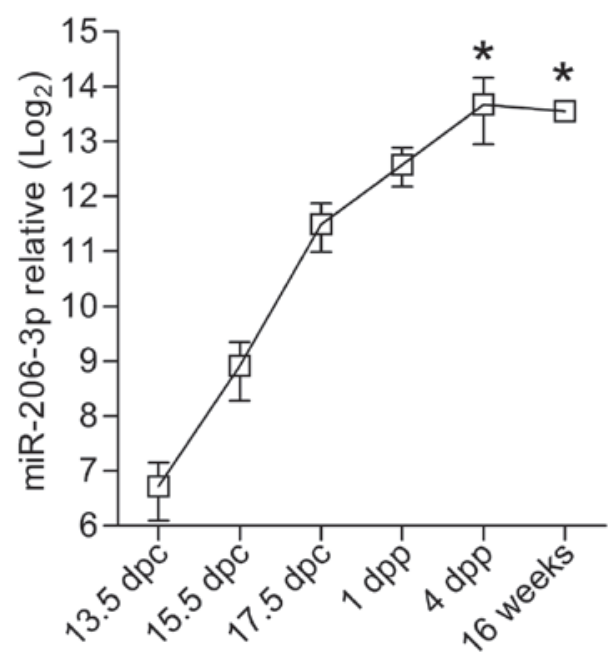

Figure 2. Relative expression levels of miR-206-3p during mouse muscle development. Subcutaneous muscle tissues of wide-type BALB/c mice at $13.5 \mathrm{dpc}, 15.5 \mathrm{dpc}, 17.5 \mathrm{dpc}, 1 \mathrm{dpp}, 4 \mathrm{dpp}$ and 16 weeks postpartum were measured for the expression of miR-206-3p, normalized to Snord68 using reverse transcription-quantitative polymerase chain reaction analyses. All relative expression data are plotted in $\log _{2}$ scale using the mean standard deviation from three independent samples. ${ }^{*} \mathrm{P}<0.05$, vs. $13.5 \mathrm{dpc}$. dpc, days postcoitum; dpp, days postpartum; miR, microRNA. 


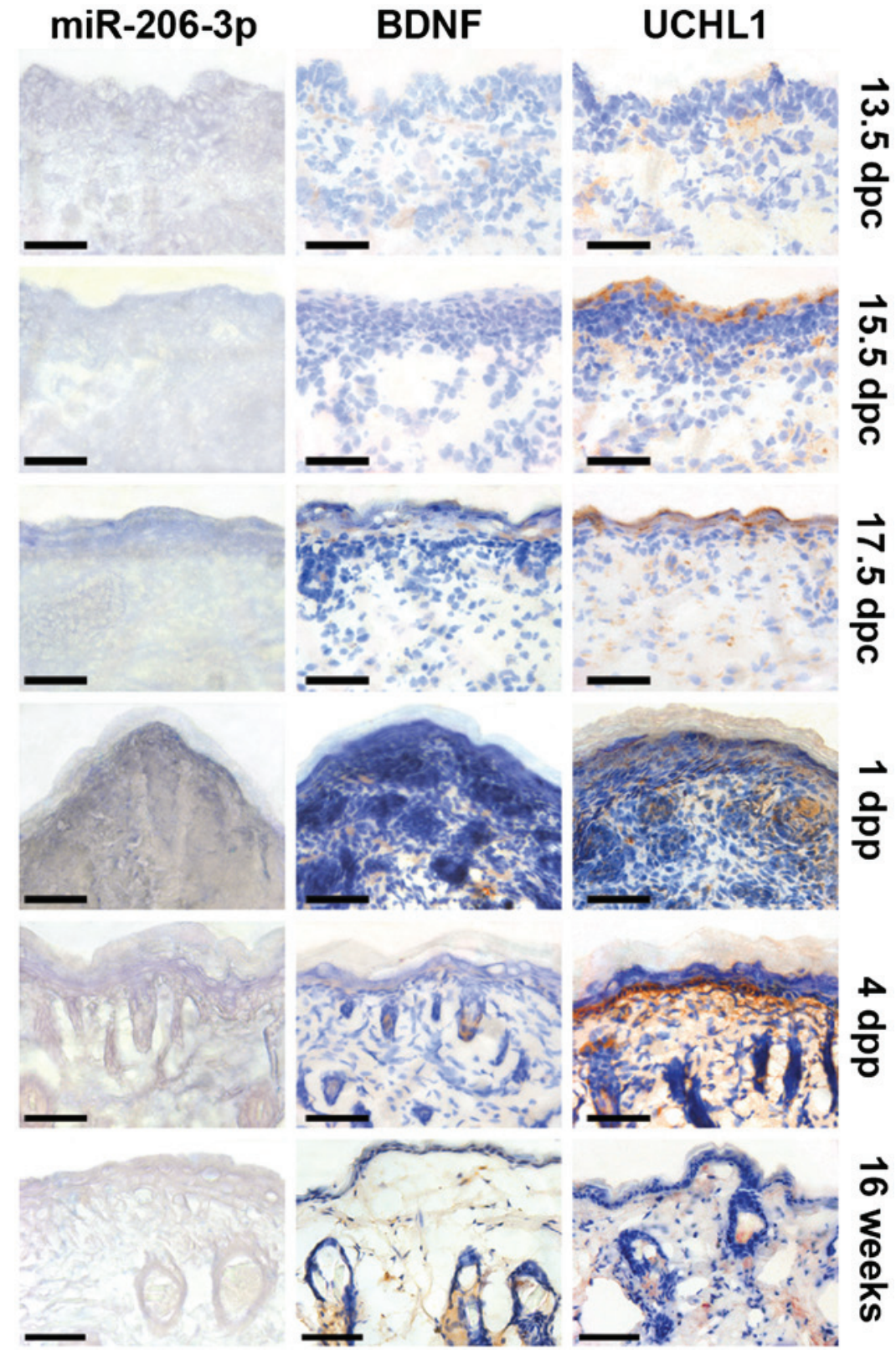

Figure 3. Tissue cryosections of skin from the backs of wide-type BALB/c mice were examined for the expression of miR-206-3p by in situ hybridization with 4-nitro-blue tetrazolium and 5-bromo-4-chloro-3'-indolylphosphate staining (dark blue). The expression levels of BDNF and UCHL1 were examined using immunohistochemistry with diaminobenzidine staining (brown) and counterstained with hematoxylin (blue). Tissues were examined at $13.5 \mathrm{dpc}, 15.5 \mathrm{dpc}$ $17.5 \mathrm{dpc}, 1 \mathrm{dpp}, 4 \mathrm{dpp}$ and 16 weeks postpartum. The expression of miR-206-3p was widespread at $13.5 \mathrm{dpc}$, and was evident in the suprabasal layer between $17.5 \mathrm{dpc}$ and $1 \mathrm{dpp}$, following which it was confined to the epidermal tissues at $4 \mathrm{dpp}$, which was located near BDNF and UCHL1. Scale bar=50 $\mu \mathrm{m}$. dpc, days postcoitum; dpp, days postpartum; miR, microRNA; BDNF, brain-derived neurotrophic factor; UCHL1, ubiquitin carboxy-terminal hydrolase L1.

the membranes were then incubated with HRP-conjugated goat anti-rabbit IgG antibody (cat. no. BA1055; Wuhan Boster Biological Technology, Ltd.) diluted 4,000-fold for $1 \mathrm{~h}$ at room temperature. Following washing, the immunolabeling proteins were reacted with chemiluminescent HRP substrate (EMD Millipore) and visualized using a ChemiDoc ${ }^{\mathrm{TM}}$ XRS system (Bio-Rad Laboratories, Inc.).

Statistical analysis. Statistical analyses were performed using Stata/SE 11.2 for Windows (StataCorp, College Station, TX, USA). Where appropriate, data are presented as the mean \pm standard deviation of at least three independent samples. Two sample's mean comparison was performed using Student's t-test. One-way analysis of variance was used to determine differences among at least three groups, and a Bonferroni multiple comparison was performed to test variances within groups. Two-tailed $\mathrm{P}<0.05$ was considered to indicate a statistically significant difference.

\section{Results}

Expression of miR-206-3p and BDNF during mouse skin development. The present study first examined the expression levels of miR-206-3p in full-thickness skin at different developmental phases. The RT-qPCR analysis indicated that the expression of miR-206-3p was low at $13.5 \mathrm{dpc}$, increased 
A

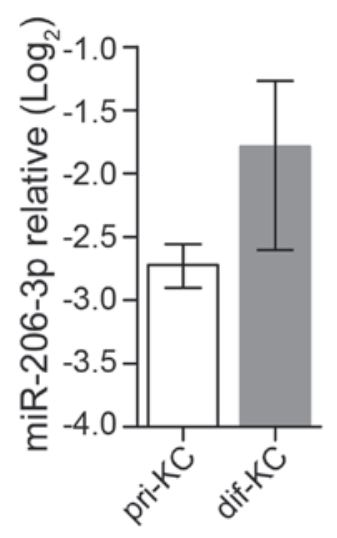

B

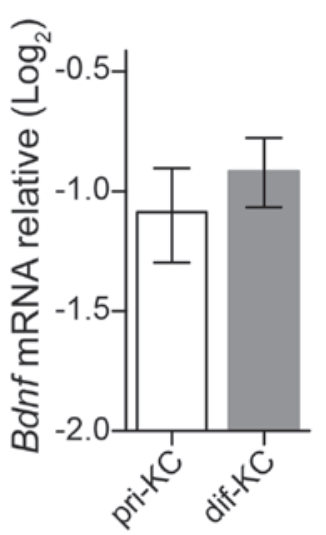

C

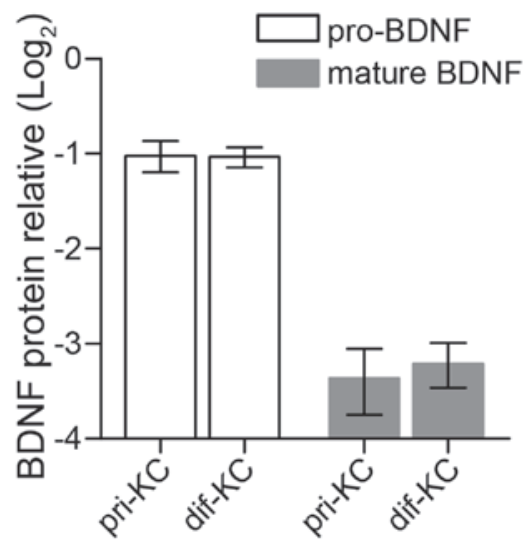

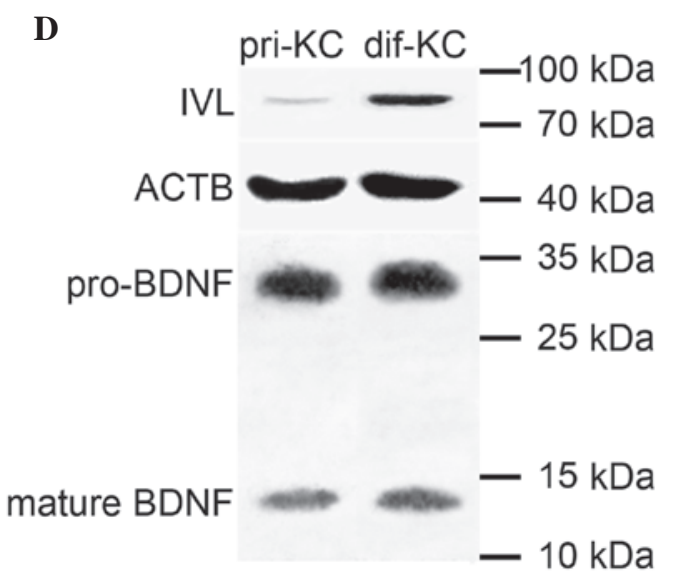

Figure 4. Keratinocytes isolated from neonatal mouse skin, cultured and induced to differentiate using $1 \mathrm{mM}$ calcium-containing growth medium. The pri-KC and dif-KC were measured for the (A) expression of miR-206-3p, normalized to Snord68 and (B) mRNA expression of Bdnf, normalized to Actb using reverse transcription-quantitative polymerase chain reaction analyse. (C and D) Protein expression of BDNF, normalized to ACTB using western blotting. All relative expression data are plotted in $\log _{2}$ scale using the mean standard deviation from three independent samples. No significant differences were found in the expression levels of either miR-206-3p or Bdnf between pri-KC and dif-KC using two-sample Student's $t$-test. pri-KC, primary keratinocytes; dif-KC, differentiated keratinocytes; miR, microRNA; BDNF, brain-derived neurotrophic factor; ACTB, $\beta$-actin; IVL anti-involucrin.

gradually by $\sim 4.5$-fold up to $17.5 \mathrm{dpc}(13.5 \mathrm{dpc}$, vs. $17.5 \mathrm{dpc}$ : $\mathrm{P}<0.001)$, and subsequently decreased to a level similar to that observed at $13.5 \mathrm{dpc}(13.5 \mathrm{dpc}$, vs. 16 weeks: $\mathrm{P}=1.000$; Fig. $1 \mathrm{~A})$. The mRNA expression level of $B d n f$ decreased until $17.5 \mathrm{dpc}$ (13.5 dpc, vs. $17.5 \mathrm{dpc}: \mathrm{P}=0.001)$ and remained at a steady level (Fig. 1B). The change in the level of BDNF precursor (pro-BDNF) was inversely correlated with that of miR-206-3p (Fig. 1C and D). The anti-BDNF antibody used in the present study was raised against a peptide mapping at the $\mathrm{N}$-terminal end of the mature form of BDNF; therefore, it reacted with multiple forms of BDNF, including pro-BDNF and a minor truncated form of the pro-BDNF (28 $\mathrm{kDa}(18)$ in the adult skin (Fig. 1D). The temporal expression pattern of mature BDNF closely resembled that of its precursor, pro-BDNF (Fig. 1C). The levels of miR-206-3p expressed in the muscle tissue was at a comparable level to that in the skin at $13.5 \mathrm{dpc}$; however, its level increased in the muscle by $>100$-fold during the neonatal period (13.5 dpc, vs. 16 weeks: $\mathrm{P}=0.001$; Fig. 2 ), confirming the muscle-specificity of miR-206-3p.

Due to its decline in expression following birth, miR-206-3p was not be considered skin-specific, as tissue-specific miRNAs have been defined to be expressed at a level $>20$-fold higher in a specific tissue, compared with the mean level of expression in all other tissues (19). However, as its expression level was inversely correlated with BDNF in the present study, the tissue distribution of miR-206-3p and BDNF were assessed. ISH showed that miR-206-3p was regionalized during skin development. The expression of miR-206-3p was widespread at $13.5 \mathrm{dpc}$, and was evident in the suprabasal layer between $17.5 \mathrm{dpc}$ and $1 \mathrm{dpp}$, following which it was confined to the epidermal tissues at $4 \mathrm{dpp}$. The expression of miR-206-3p was weakened in the adult (Fig. 3). By contrast, BDNF immunolabeling was scattered and weak at $13.5 \mathrm{dpc}$, and was barely visible at $1 \mathrm{dpp}$. Subsequently, it was expressed in the suprabasal layer and inside hair follicles, where its expression was located adjacent to, but not overlapping, that of miR-206-3p.

The pan-neuronal marker, UCHL1, also termed PGP9.5, revealed a pattern of cutaneous innervation made by nerve fibers. The nerve fibers innervated and reached the epidermal surface at high density by $17.5 \mathrm{dpc}$, however they subsequently became predominantly subepidermal, which resembled the distribution of miR-206-3p, until $1 \mathrm{dpp}$. Following this, the localizations of UCHL1 and miR-206-3p were separate, but remained near each other (Fig. 3). 
Expression of $\mathrm{miR}-206-3 p$ and BDNF during keratinocyte differentiation in vitro. To determine whether the expression of miR-206-3p was dependent on epidermal differentiation, in vitro calcium-induced differentiation of primary keratinocytes was performed. No significant differences were found in the expression of either miR-206-3p $(\mathrm{P}=0.227)$ or $B d n f(\mathrm{P}=0.118)$; mature $\mathrm{BDNF}(\mathrm{P}=0.106)$ or pro-BDNF $(\mathrm{P}=0.905)$ between the primary and differentiated keratinocytes (Fig. 4A-C), suggesting that they were not involved in keratinocyte differentiation. However, the elevated expression of IVL in the differentiated keratinocytes verified the in vitro differentiation model (Fig. 4D).

\section{Discussion}

During mouse development, miR-206-3p is first detected at low levels, as early as $9.5 \mathrm{dpc}$, using northern blotting and the cloning frequency of the whole embryo (20). It is then primarily restricted to skeletal muscle in the adult (21). miR-206-3p has also been detected in adult skin $(3,10,11)$, where it is expressed at a quarter of the level expressed in $12.5 \mathrm{dpc}$ skeletal muscle (12). For the first time, to the best of our knowledge, the present study demonstrated the spatiotemporal expression of miR-206-3p in skin. The results of the present study revealed that miR-206-3p was expressed dynamically during mouse skin development, with its level increasing from $13.5 \mathrm{dpc}$, peaking at $17.5 \mathrm{dpc}$ and declining following birth. The fluctuation in the expression of miR-206-3p was accompanied by an inverse change in the protein level of its $B d n f$ target gene However, the mRNA expression levels of $B d n f$ did not parallel with its protein expression levels. The tissue distribution of miR-206-3p was similar or located adjacent to that of UCHL1 during skin development, suggesting the potential involvement of miR-206-3p in cutaneous innervation.

It is commonly observed that the majority of miRNAs are not essential for tissue establishment, but are important for late tissue differentiation and maintenance (22); however, the declining expression level of miR-206-3p in postnatal skin in the present study suggested that it may not be associated with cutaneous maturation. In addition, the pattern of miR-206-3p distribution, which did not indicate skin-specificity, also supports this assumption. The in vitro keratinocyte model demonstrated that miR-206-3p was independent of keratinocyte differentiation. These findings, together with previous evidence indicating miR-206-3p involvement in muscle innervation $(2,9)$, led the present study to investigate the possible role of miR-206-3p during skin innervation. A previous study clearly demonstrated that $B d n f$ is directly suppressed by miR-206 during myogenic differentiation, underlining a retrograde regulatory role of miR-206 at the neuromuscular junction (23). Of note, BDNF is capable of mediating neuronal differentiation and growth, synapse formation and plasticity, and higher cognitive functions in the mammalian brain (24). It has been shown that keratinocyte-derived BDNF is essential for the innervation of hair follicles and development of Meissner corpuscles $(25,26)$. Therefore, the bell-shaped expression pattern of miR-206-3p during skin development is likely attributed to two consecutive and overlapping processes of innervation: i) all sensory terminals transiently hyperinnervate the skin and penetrate to the epidermal surface prior to retracting subepidermally at a late embryonic stage (27); ii) the hair follicle keratinocytes begin to concentrate in newly developed follicular innervation sites when intra-epidermal nerve fiber endings are present (28), during which miR-206-3p may exert its neuromodulation through the post-transcriptional suppression of $B d n f$. Although the production of mature BDNF was almost parallel to that of its precursor during this time frame, its level of expression was lower at $13.5 \mathrm{dpc}$ and higher in the adult stage, compared with that of pro-BDNF. This suggested that other mechanisms, including post-translational processing or endocytic uptake, may involved in regulating the level of mature BDNF, which is available for the innervation and early postnatal survival of cutaneous sensory organs $(25,29)$.

The results of the present study suggested that upregulation in the expression of miR-206-3p at late embryonic stages suppressed the expression of BDNF and induced the hyperinnervated fibers to retract. The subsequent decline in the expression levels of miR-206-3p then enabled the levels of BDNF to increase to meet the requirements of the newly developed follicular innervations. In conclusion, these findings indicated a potential role of miR-206-3p in cutaneous innervation, which is largely mediated by the neurotrophic support of BDNF. These findings may revise current understanding of this muscle-specific miRNA, and adds support to the possibility that miRNAs have functions in addition to those, which are predominant. Cutaneous innervation requires examination from the perspective of miRNAs, and this mechanism may be amenable for the development of possible therapeutic approaches.

\section{Acknowledgements}

This study was partially supported by a grant from the Postgraduate's Innovation Project of Jiangsu Province, China to Dr Yuan Mu (grant. no. CXLX11_0606).

\section{References}

1. McCarthy JJ: MicroRNA-206: The skeletal muscle-specific myomiR. Biochim Biophys Acta 1779: 682-691, 2008.

2. Velleca MA, Wallace MC and Merlie JP: A novel synapse-associated noncoding RNA. Mol Cell Biol 14: 7095-7104, 1994.

3. Anderson C, Catoe $\mathrm{H}$ and Werner R: MIR-206 regulates connexin43 expression during skeletal muscle development. Nucleic Acids Res 34: 5863-5871, 2006.

4. Kim HK, Lee YS, Sivaprasad U, Malhotra A and Dutta A: Muscle-specific microRNA miR-206 promotes muscle differentiation. J Cell Biol 174: 677-687, 2006.

5. Rosenberg MI, Georges SA, Asawachaicharn A, Analau E and Tapscott SJ: MyoD inhibits Fstll and Utrn expression by inducing transcription of miR-206. J Cell Biol 175: 77-85, 2006.

6. Chen JF, Tao Y, Li J, Deng Z, Yan Z, Xiao X and Wang DZ: MicroRNA-1 and microRNA-206 regulate skeletal muscle satellite cell proliferation and differentiation by repressing Pax7. J Cell Biol 190: 867-879, 2010.

7. Winbanks CE, Wang B, Beyer C, Koh P, White L, Kantharidis P and Gregorevic P: TGF-beta regulates miR-206 and miR-29 to control myogenic differentiation through regulation of HDAC4. J Biol Chem 286: 13805-13814, 2011.

8. Williams AH, Valdez G, Moresi V, Qi X, McAnally J, Elliott JL, Bassel-Duby R, Sanes JR and Olson EN: MicroR NA-206 delays ALS progression and promotes regeneration of neuromuscular synapses in mice. Science 326: 1549-1554, 2009. 
9. Radzikinas K, Aven L, Jiang Z, Tran T, Paez-Cortez J, Boppidi K, Lu J, Fine A and Ai X: A Shh/miR-206/BDNF cascade coordinates innervation and formation of airway smooth muscle. J Neurosci 31: 15407-15415, 2011.

10. Hufbauer M, Lazić D, Reinartz M, Akgül B, Pfister H and Weissenborn SJ: Skin tumor formation in human papillomavirus 8 transgenic mice is associated with a deregulation of oncogenic miRNAs and their tumor suppressive targets. J Dermatol Sci 64: 7-15, 2011.

11. Georgantas RW III, Streicher K, Luo X, Greenlees L, Zhu W, Liu Z, Brohawn P, Morehouse C, Higgs BW, Richman L, et al: MicroRNA-206 induces G1 arrest in melanoma by inhibition of CDK4 and Cyclin D. Pigment Cell Melanoma Res 27: 275-286, 2014

12. Mu Y, Zhou H, Li W, Hu L and Zhang Y: Evaluation of RNA quality in fixed and unembedded mouse embryos by different methods. Exp Mol Pathol 95: 206-212, 2013.

13. Yi R, Poy MN, Stoffel M and Fuchs E: A skin microRNA promotes differentiation by repressing 'stemness'. Nature 452 225-229, 2008.

14. Hildebrand J, Rütze M, Walz N, Gallinat S, Wenck H, Deppert W, Grundhoff A and Knott A: A comprehensive analysis of microRNA expression during human keratinocyte differentiation in vitro and in vivo. J Invest Dermatol 131 : 20-29, 2011

15. Wang WX, Wilfred BR, Baldwin DA, Isett RB, Ren N, Stromberg A and Nelson PT: Focus on RNA isolation: Obtaining RNA for microRNA (miRNA) expression profiling analyses of neural tissue. Biochim Biophys Acta 1779: 749-757, 2008

16. Tang F, Hayashi K, Kaneda M, Lao K and Surani MA: A sensitive multiplex assay for piRNA expression. Biochem Biophys Res Commun 369: 1190-1194, 2008.

17. Livak KJ and Schmittgen TD: Analysis of relative gene expression data using real-time quantitative PCR and the 2(-Delta Delta C(T)) Method. Methods 25: 402-408, 2001.

18. Mowla SJ, Farhadi HF, Pareek S, Atwal JK, Morris SJ, Seidah NG and Murphy RA: Biosynthesis and post-translational processing of the precursor to brain-derived neurotrophic factor. J Biol Chem 276: 12660-12666, 2001
19. Lee EJ, Baek M, Gusev Y, Brackett DJ, Nuovo GJ and Schmittgen TD: Systematic evaluation of microRNA processing patterns in tissues, cell lines and tumors. RNA 14: 35-42, 2008.

20. Takada S, Berezikov E, Yamashita Y, Lagos-Quintana M, Kloosterman WP, Enomoto M, Hatanaka H, Fujiwara S, Watanabe H, Soda M, et al: Mouse microRNA profiles determined with a new and sensitive cloning method. Nucleic Acids Res 34: e115, 2006.

21. Sempere LF, Freemantle S, Pitha-Rowe I, Moss E, Dmitrovsky $\mathrm{E}$ and Ambros V: Expression profiling of mammalian microRNAs uncovers a subset of brain-expressed microRNAs with possible roles in murine and human neuronal differentiation. Genome Biol 5: R13, 2004.

22. Wienholds E and Plasterk RH: MicroRNA function in animal development. FEBS Lett 579: 5911-5922, 2005.

23. Miura P, Amirouche A, Clow C, Bélanger G and Jasmin BJ: Brain-derived neurotrophic factor expression is repressed during myogenic differentiation by miR-206. J Neurochem 120: 230-238, 2012

24. Park H and Poo MM: Neurotrophin regulation of neural circuit development and function. Nat Rev Neurosci 14: 7-23, 2013.

25. LeMaster AM, Krimm RF, Davis BM, Noel T, Forbes ME, Johnson JE and Albers KM: Overexpression of brain-derived neurotrophic factor enhances sensory innervation and selectively increases neuron number. J Neurosci 19: 5919-5931, 1999.

26. González-Martínez T, Fariñas I, Del Valle ME, Feito J, Germanà $\mathrm{G}$, Cobo $\mathrm{J}$ and Vega JA: BDNF, but not NT-4, is necessary for normal development of Meissner corpuscles. Neurosci Lett 377: 12-15, 2005.

27. Jackman A and Fitzgerald M: Development of peripheral hindlimb and central spinal cord innervation by subpopulations of dorsal root ganglion cells in the embryonic rat. J Comp Neurol 418: 281-298, 2000

28. Peters EM, Botchkarev VA, Müller-Röver S, Moll I, Rice FL and Paus R: Developmental timing of hair follicle and dorsal skin innervation in mice. J Comp Neurol 448: 28-52, 2002.

29. Valdés-Sánchez T, Kirstein M, Pérez-Villalba A, Vega JA and Fariñas I: BDNF is essentially required for the early postnatal survival of nociceptors. Dev Biol 339: 465-476, 2010 